\title{
Quality Indicators in Laboratory Medicine
}

\author{
Ramune Sepetiene MD, PhD* \\ Area Medical Director, Abbott GmbH, Germany \\ *Corresponding author: Ramune Sepetiene MD, PhD, Area Medical Director, Abbott GmbH, Germany. \\ To Cite This Article: Ramune Sepetiene MD, PhD. Quality Indicators in Laboratory Medicine. Am J Biomed Sci \& Res. 2021 - 14(6). AJBSR. \\ MS.ID.002059. DOI: 10.34297/AJBSR.2021.14.002059.
}

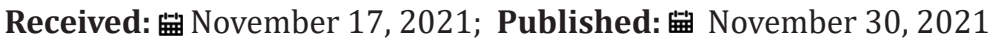

\section{Opinion}

We are still under discussion about Quality issues in nowadays laboratories despite their super technical and robotically packed equipment. It seems that all fully automated systems generate the same issues as many years ago when laboratories mainly been equipped with semiautomated machines or totally manually procedures took place on a bench. Bearing in mind that human errors will be still possible while even single person operate any process or any step within laboratory, the Quality Indicators (QI) calculation and monitoring will be under control of the members of staff. Routine testing requires maximum strength everyday while Quality Management requires not only enough time to perform procedures at excellent manner but also relevant knowledge and skills. This short Opinion article should be helpful to create own laboratory Quality Indicators design and subsequent monitoring.

The initiatives for quality assurance and quality improvement in clinical laboratories has been forced mainly by the requirements of regulatory and accrediting bodies. Many of them used to follow the Design/Measure/Assess/Improve model for effective management of their processes according to the National Institute of Standards and technology, implemented at the end of last century [1]. For visualization of errors laboratories started to use very popular Six Sigma methodology, very well described by Dr. James Westgard [2] known as Westgard rules which were created for wide professional use in 1981.

Moreover, the last 30 years for Laboratory Medicine is possible to call Quality Focused period.Starting with ISO standardization from the ISO/TC212- predecessor for nowadays ISO 15189Particular requirements for quality and competence for Clinical laboratory testing and in vitro diagnostic test systems, which one was prepared and published its first edition in 2003 and second - shortly after four years [3]. Now we have the ISO 15189, the latest version published in 2012. Following the standardization requirements each clinical laboratory utilizes this standard for their own guidelines and procedures to obtain the quality-based results. There are sufficient sets of requirements to be followed by clinical laboratories worldwide. The most relevant to the need and the spirit of today's laboratory is Clinical Laboratory Standardization Institute (CLSI) managing the Global Laboratory Standards, while Clinical Laboratory Improvement Amendments (CLIA) include federal standards applicable to all US facilities or sites which test human specimens. According to very popular opinion, the existing multitude requirements including national legislation regulations presupposes variability of actions creating own Quality Measurement Design.

Following the existing insights and recommendations to harmonize clinical laboratory quality model [4] by implementing a scientifically based Quality Control system [5] and use of processes design, could be useful to have this template as manual to create an individual one (Table1). Assessing and monitoring each indicator value worth to use previously, at least for one year period, known and systematized own register of non- conformities. Also, very useful to divide indicators to sub indicators, if laboratory monitors, for example, separated HIL cases or any other examples of nonconformities. Estimating that majority of errors occur within Preanalytical phase, about $60 \%$ of total laboratory errors, the rest phases assume to be less erroneous. 


\begin{tabular}{|c|c|c|}
\hline Laboratory Process & Quality Indicators & $\begin{array}{l}\text { Monitoring Value, According to The } \\
\text { Previously Established (6), \% }\end{array}$ \\
\hline $\begin{array}{c}\text { Preanalytical phase, } 5 \text { S } \\
\text { S }\end{array}$ & $\begin{array}{l}\text { Sample identification errors } \\
\text { Sample type errors } \\
\text { Sample filling errors } \\
\text { *Sample HIL } \\
\text { Sample transportation errors }\end{array}$ & $55-65$ \\
\hline $\begin{array}{r}\text { Analytical phase, 5E } \\
\qquad \mathrm{E}\end{array}$ & $\begin{array}{l}\text { Errors with calibrators } \\
\text { Errors with controls } \\
\text { Errors with sample testing } \\
\text { Errors with testing equipment } \\
\text { Errors with data transcription }\end{array}$ & $15-20$ \\
\hline $\begin{array}{c}\text { Postanalytical phase, 5I } \\
\text { I }\end{array}$ & $\begin{array}{l}\text { Inappropriate turnaround time } \\
\text { Inappropriate results handling } \\
\text { Incorrect report } \\
\text { Incorrect comments } \\
\text { Invalid result }\end{array}$ & $15-20$ \\
\hline Other impact & $\begin{array}{l}\text { *Variable staff incompetence, } \\
\text { property functionality, outside the lab non- } \\
\text { compliances }\end{array}$ & Variable value \\
\hline
\end{tabular}

At the beginning it is necessary to determine the figures of probability that moving upwards would immediately mean noncompliance or by opposite manner- that moving down means nonacceptable criteria for positive compliance report: less than the defined value or not more than the defined value See below (Table2). At the end of each year a laboratory should obtain one Summary table of 12 monthly generated tables. The finally established results must be used for next year estimates calculation. The proposed QI monitoring design does not attempt to be the only one available or the best approach to perform quality tasks. Each laboratory must use its own design according to the testing profile and tools of implemented Quality Management System [6].

\begin{tabular}{|c|c|c|c|}
\hline Quality Indicator & Value Set & Value Measured & Conclusion \\
\hline Sample identification errors & $\leq 10$ & 8 & Compliance \\
\hline Sample type errors & $\leq 5$ & 9 & Non-compliance \\
\hline Sample filling errors & $\leq 5$ & 2 & Compliance \\
\hline Sample HIL* & $\leq 10$ & 8 & Compliance \\
\hline Sample transportation errors & $\leq 6$ & 5 & Compliance \\
\hline Errors with calibrators & $\leq 2$ & 1 & Compliance \\
\hline Errors with controls & $\leq 3$ & 2 & Compliance \\
\hline Errors with sample testing & $\leq 4$ & 5 & Non-compliance \\
\hline Errors with testing equipment & $\leq 1$ & 1 & Compliance \\
\hline Errors with data transcription & $\leq 2$ & 2 & Compliance \\
\hline Inappropriate turnaround time & $\leq 2$ & 3 & Non-compliance \\
\hline Inappropriate results handling & $\leq 2$ & 4 & Non-compliance \\
\hline Incorrect report & $\leq 3$ & 2 & Compliance \\
\hline Incorrect comments & $\leq 1$ & 1 & Compliance \\
\hline Invalid result & $\leq 2$ & 2 & Compliance \\
\hline Variabilities & $\leq 1$ & 0 & Compliance \\
\hline
\end{tabular}

\section{References}

1. National Institute of Standards and Technology (1999) Malcolm Baldridge National Quality Award Criteria for Performance Excellence Gaithersburg, USA.

2. Carroll TA, Pinnick HA, Carroll WE (2003) Probability and the Westgard Rules. Ann Clin Lab Sci 33(1): 113-114.

3. Kawai T (2010) [History of ISO 15189 and its future perspectiv]. Rinsho Byori 58(1): 64-68.
4. Plebani M, Astion ML, Barth JH, Chen W, de Oliveira Galoro CA, et al. (2014) Harmonization of quality indicators in laboratory medicine. A preliminary consensus. Clin Chem Lab Med 52(7): 951-958.

5. Westgard JO, Westgard SA (2016) Quality control review: implementing a scientifically based quality control system. Annals of Clinical Biochemistry 53(1): 32-50.

6. Sepetiene (2021) Preanalytical phase for transfusion medicine and blood bank laboratory - tasks to complete, manuscript under consideration of OARJ. 